\title{
ESTUDO DE CASO: REPROVAÇÕES POR TORQUE ELEVADO NO APERTO DO VOLANTE DE UM MOTOR LEVE DO CICLO OTTO.
}

\author{
Cristian Carlo Gonçalves da Costa ${ }^{1}$, Renato Penteado ${ }^{2}$, Carlo Giuseppe Filippin ${ }^{2}$ \\ ${ }^{1}$ Mestrado Profissional em Desenvolvimento de Tecnologia \\ ${ }^{2}$ Institutos Lactec
}

E-mails: cristiancosta2002@yahoo.com.br, renato@lactec.org.br, filippin@lactec.org.br.

\section{RESUMO}

O artigo apresenta um estudo de caso desenvolvido em uma fábrica de motores do ciclo Otto, na qual foi detectada uma oportunidade de melhoria relacionada à fixação do volante do motor ao virabrequim. Esse processo é extremamente importante, uma vez que essa peça transfere o torque gerado no virabrequim, através das explosões do carburante, para a caixa de câmbio do veículo.

O processo de fixação do volante do motor no virabrequim é dividido em duas etapas, onde em cada etapa quatro parafusos são apertados simultaneamente em dois ciclos idênticos por meio de um conjunto composto por quatro apertadeiras de alta tecnologia. Esse processo de aperto segue um método definido em normas de engenharia.

Durante a montagem automatizada, verificou-se que alguns dos oito parafusos apresentavam torque acima do previsto em norma de engenharia, levando à reprovação do ciclo e gerando perdas por microparadas de linha e refugos.

O problema foi resolvido e sua solução exigiu uma mudança de mentalidade e um estudo de materiais e de processos de fabricação com enfoque na pesquisa científica, exigindo um estudo acadêmico aprofundado dos conceitos de tribologia, torque, rugosidade, coeficiente de atrito, acabamento superficial, gradiente de torque e métodos de aperto.

O artigo foi fundamentado em dados, medidas de Laboratório de Metrologia, tratamentos estatísticos, imagens, avaliação de perdas e aponta para a solução do problema, trazendo em seu desenvolvimento análises e comparações de desempenho entre acabamentos superficiais de Oxidação Negra, Oleamento e Fosfatização medidos através da Análise de Capabilidade do Gradiente de Torque, trazendo como resposta o melhor acabamento superficial de parafuso para 0 processo de aperto analisado.

\section{INTRODUÇÃO}

A empresa em questão tem como negócio produzir motores nas versões 1.6/1.8 litros, ambos com 16 válvulas, destinados ao mercado interno e externo, utilizando 
desde 2009 o Sistema de Gestão chamado World Class Manufacturing, conhecido como WCM, e que segundo o Guia de Pilares Técnicos (2008) [1], tem como premissa a cultura e a adoção de práticas, ferramentas e metodologias que visam fortemente à redução de perdas e custos com aumento de produtividade, através da excelência na integração e desenvolvimento do ser humano aos processos.

É neste cenário, com agressivo foco na redução de custos e ganho de desempenho, que na linha de montagem de motores desta empresa surgiu a oportunidade de estudo para proposição de melhorias.

$\mathrm{Na}$ linha final de montagem chamada Dressup montam-se alguns periféricos no motor como chicote, borboleta, embreagem e o volante do motor. É na montagem desta última que se encontra o processo de aperto que é objeto deste estudo.

O volante do motor é uma peça de material pesado e robusto fixada por oito parafusos diretamente no virabrequim do motor conforme mostrado na FIGURA 1.

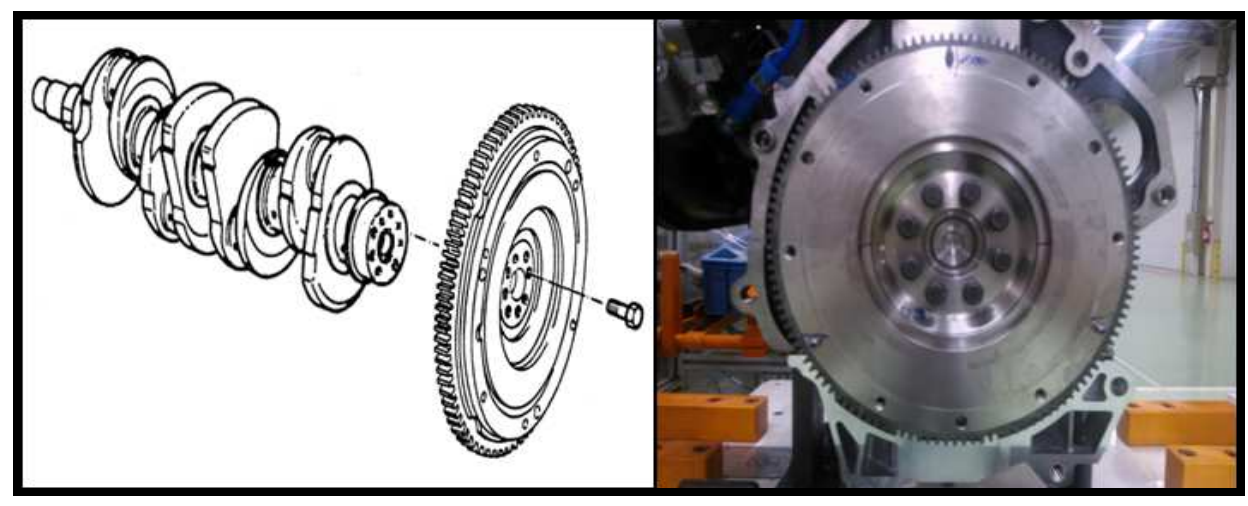

FIGURA 1 - Volante do motor

FONTE: Cristian Carlo Gonçalves da Costa (2014)

Este aparafusamento é extremamente importante, uma vez que esta peça transfere o torque gerado no virabrequim, através das explosões do carburante, para a caixa de câmbio do veículo. Também é contra o volante do motor que a embreagem atua mecanicamente, fazendo pressão sobre este, permitindo ou impedindo a transferência de energia mecânica para a caixa de câmbio.

O processo de aparafusamento do volante do motor no virabrequim é dividido em duas etapas. Em cada etapa, quatro parafusos são apertados simultaneamente em dois ciclos idênticos por meio de um conjunto composto por quatro apertadeiras de alta tecnologia, conforme um programa de torque definido manualmente no software da máquina, o qual tem tem suas etapas, tipo e parâmetros de controle, e valores finais de torque e ângulo padronizados e definidos segundo normas de engenharia da empresa [2] e [3].

Este processo de aperto, desde o ano de 2009, tem apresentado problemas de rejeição devido à reprovação por torque alto, ou seja, torque além do limite superior da janela de aprovação, porém o aumento de volume na produção a partir de 2011, de 450 para 900 motores dia, trouxe também um grande acréscimo nas reprovações, com aumento considerável das perdas. Estas perdas do ano de 2011 
até o ano 2014, traduzidas em microparadas de máquina e custos em tempo de mão de obra disponível ociosa além dos refugos de parafusos com as reprovações realizadas, traduzem um volume de motores deixados de produzir em aproximadamente 22.523 unidades, ou seja, um mês de produção em capacidade máxima somente na área de Montagem.

As análises anteriores não foram devidamente aprofundadas e, via de regra, dependeram do auxílio de consultores externos para dar treinamento de conceitos, devido ao pouco conhecimento na região Sul do País, lembrando que os grandes especialistas em parafusos e técnicas de aperto hoje se encontram na região Sudeste do Brasil.

Também vale ressaltar que, segundo Nascimento Jr. [4], existe pouca literatura científica e acadêmica específica, disponibilizada aos ambientes industriais, que poderiam auxiliar no desenvolvimento técnico de profissionais e engenheiros, e as pesquisas e soluções técnicas aplicadas a resoluções de problemas são sigilosas e restritas às empresas.

É neste cenário que se viu a oportunidade de entender a causa ou as causas do problema apresentado, bem como apresentar soluções para o mesmo, e desenvolver um aprendizado para se levar uma nova abordagem de análise para o meio industrial, onde se possa criar uma visão mais técnica através do estudo teórico para aprofundar, entender e melhorar as práticas de análise até então limitadas.

O objetivo geral deste estudo de caso foi avaliar e definir a causa ou o conjunto das possíveis causas que geram o problema de reprovação por torque, mais especificamente por torque alto, e propor solução ou soluções práticas que possam eliminar o problema.

\section{METODOLOGIA}

\section{ANÁLISE DAS CURVAS DE APERTO}

Utilizando os recursos gráficos do software BS 300 do sistema de parafusamento Bosch Rexroth System 300 foram coletados e avaliados os dados de torque de diferentes meses durante os anos de 2014 e 2015 com intuito de avaliar a capacidade do processo.

Também foram utilizados os recursos do Sistema Bosch Rexroth System 300, para avaliar e comparar as curvas que se encontravam aprovadas dentro dos limites inferior e superior de torque, chamadas ao longo do estudo de "curvas OK" e as que apresentavam reprovações por torque além do limite superior, gerando reprovações, chamadas "curvas NOK", no sistema gráfico.

\section{AVALIAÇÃO DO PROCESSO DE APERTO (CHÃO DE FÁBRICA)}

Após os estudos teóricos realizados nos itens anteriores, foram realizadas diversas observações no posto de trabalho desde a pré-montagem manual dos parafusos até o torque automático dos mesmos no volante, seguindo o sistema 
de Diagrama de Ishikawa [1], que permite classificar as prováveis causas dos problemas em seis tipos diferentes quando aplicada a metodologia 6M.

Também, com intuito de visualizar e observar a condição de superfície das peças antes e depois da montagem foi utilizada unidade de medição Optiv Classic, utilizada para medição de pequenas peças em 3D com aumento total de até $45 \mathrm{X}$.

\section{AUDITORIA FOCADA NO PROCESSO DE FABRICAÇÃO DO PARAFUSO E NO PROCESSO DE OLEAMENTO DO PARAFUSO (FINIGARD105)}

Foi realizada uma auditoria focada no fornecedor de parafusos e no fornecedor responsável pela aplicação do acabamento final superficial no parafuso, com intuito de conhecer o processo [5] e avaliar possibilidades de melhoria.

\section{ESTUDO COMPARATIVO DE APERTOS DO VOLANTE ATUAL, COM ÓLEO SAE 20W/40 E DO APERTO DO FLEXPLATE}

Foram realizados testes comparativos em três situações distintas para avaliar as condições de interação e processo de torque e gradiente de torque [6] com intuito de melhor compreender as possíveis causas do fenômeno em análise, conforme abaixo:

Situação 1: coleta de dados no processo de torque atual;

Situação 2: coleta de dados realizada aplicando uma fina camada de óleo SAE $20 \mathrm{~W} / 40$ no volante, somente na região de assento da flange do parafuso;

Situação 3: coleta de dados no processo de torque do flexplate (peça montada no lugar do volante para motores automáticos).

\section{ESTUDO COMPARATIVO DA RUGOSIDADE DAS PEÇAS}

Para realizar o estudo [7, 8 e 9] comparativo foram utilizadas peças de diferentes lotes de volante e flexplate, os quais foram medidos os parâmetros de amplitude $\mathrm{Ra}, \mathrm{Rt}$ e Rz, conforme definição abaixo:

Ra é a média das rugosidades médias calculadas em cada cutt-off (comprimento de amostragem);

Rt é a máxima distância vertical entre o pico mais alto e o vale mais profundo no comprimento de medição total, sem levar em conta os valores parciais de cada cutt-off (comprimento de amostragem);

$R z$ é o valor médio das máximas distâncias verticais entre o pico mais alto e o vale mais profundo calculados em cada cutt-off (comprimento de amostragem)

Para tanto utilizou-se a máquina de medições de rugosidade e formas Talysurf Series i60, com resolução do sistema de $0,25 \mu \mathrm{m}$ e 120.000 pontos de capacidade por medição. Para o volante foram utilizados 5 cut-offs de $0,25 \mathrm{~mm}$ num comprimento de avaliação total de $1,6 \mathrm{~mm}$ em três pontos distintos (FIGURA 2). Já para o flexplate foram utilizados 5 cut-offs de $0,80 \mathrm{~mm}$ num comprimento de avaliação total de $4,9 \mathrm{~mm}$ em três pontos distintos (FIGURA 2). 


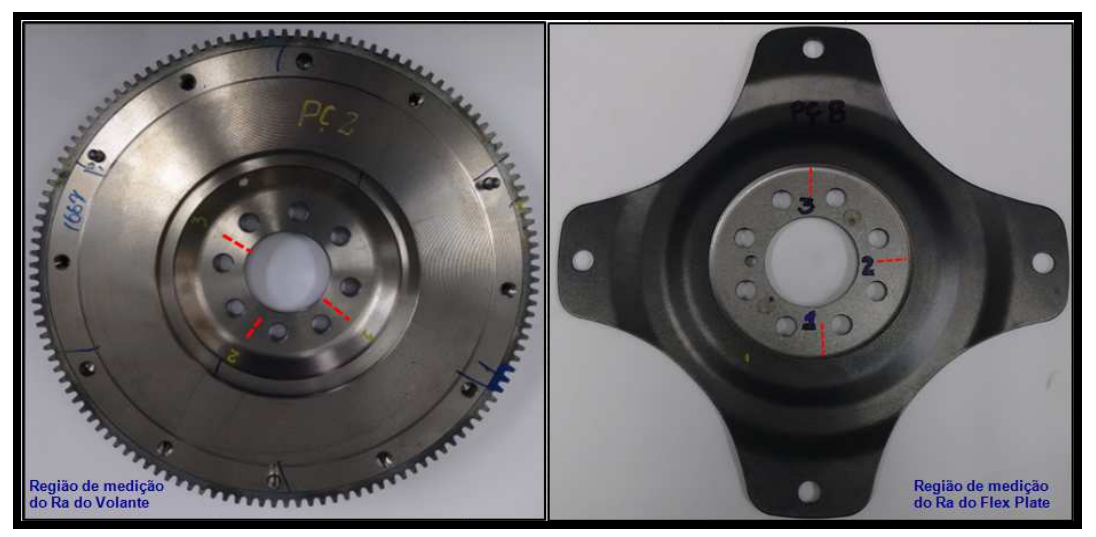

FIGURA 2 - Região de medição de rugosidade Volante e FlexPlate FONTE: Cristian Carlo Gonçalves da Costa (2015)

No caso do parafuso foram medidas 5 peças utilizando 5 cut-offs de $0,08 \mathrm{~mm}$ num comprimento de avaliação total de $0,58 \mathrm{~mm}$ em três pontos distintos.

Também foram medidos os parâmetros híbridos HSC e RPc, onde foram utilizados novos lotes de 7 unidades do volante e 7 unidades do flexplate. Já para o parafuso foram medidas as mesmas 5 peças utilizadas na medição dos parâmetros de amplitude. Para HSC a altura média ou valor de referência utilizada para medições foi o valor $0 \mu \mathrm{m}$ para análise, ou seja, o cálculo do número de picos acima desse valor a partir da linha vermelha que passa na origem e para o RPc foi utilizado uma largura de faixa (área delimitada por $\mathrm{C} 1 \mathrm{e}$ C2) no valor de $1 \mu \mathrm{m}$ com centro na origem. A quantidade de cut-offs e dimensões de medição foram as mesmas utilizadas nas medições dos parâmetros de amplitude

\section{ESTUDO COMPARATIVO DE ALONGAMENTO DO PARAFUSO COM E SEM ÓLEO SAE 20W/40}

Para fazer uma análise comparativa dos alongamentos após o torque normal e torque com óleo SAE 20W/40 foi realizada a coleta de dados do comprimento do parafuso antes e depois do torque em ambas as condições. Para tanto foi utilizado o traçador de altura Digimar CX1, com capacidade de medição de 600 $\mathrm{mm}$ com resolução de $0.0001 \mathrm{~mm}$.

\section{ESTUDO DE IMPLANTAÇÃO DE NOVO ACABAMENTO SUPERFICIAL}

Durante os estudos, a Engenharia da empresa em questão se propôs a ajudar na mudança de tratamento superficial com intuito de resolver os problemas de reprovação por torque acima do limite superior. Assim, foram realizados testes práticos com coleta de 250 curvas e valores de apertos utilizando amostras de parafusos com acabamento superficial "fosfatizado", com objetivo de alterar o acabamento atual, e estabelecer uma solução que atenda aos requisitos de engenharia. Também foram avaliados os parâmetros de rugosidade de 5 parafusos fosfatizado e as superfícies das peças antes e depois do processo de torque, utilizando a mesma metodologia anterior, com intuito de avaliar o resultado da interação das peças com o novo acabamento. 


\section{ESTUDO DE CASO E RESULTADOS}

A coleta de dados de torque do processo atual (Situação 1), foi submetida à ferramenta estatística de Análise de Capabilidade de Processo onde 0 valor esperado para os índices $\mathrm{Cp}$ e Cpk é de no mínimo 1,33. Porém, como pode ser observado na FIGURA 3, se obteve um Cp próximo do ideal $(1,26)$, ou seja, uma baixa variação em relação aos limites de torque. Quanto ao Cpk foi obtido um resultado de 0,67, indicando uma variação muito descentralizada (curva de distribuição deslocada) em relação aos limites especificados, caracterizando assim um processo ineficaz.

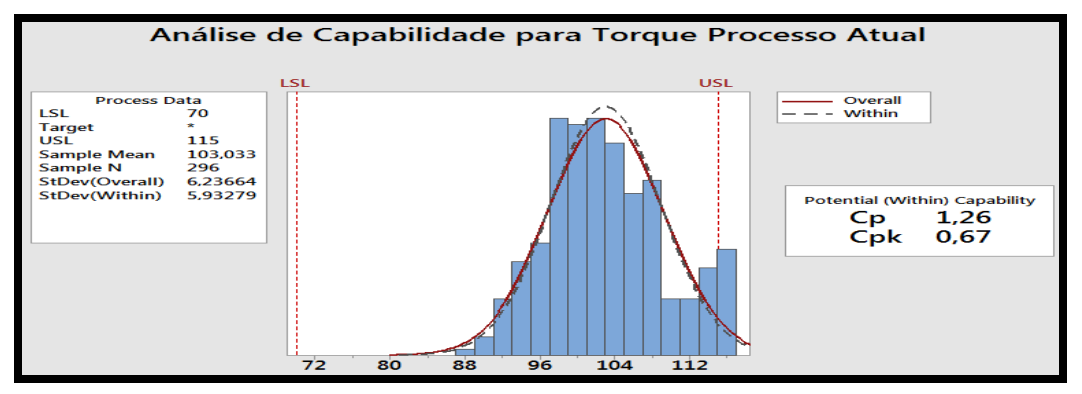

FIGURA 3 - Análise de Capabilidade do Processo de Aperto Atual FONTE: Cristian Carlo Gonçalves da Costa (2015)

Em seguida foram avaliadas primeiramente as curvas de aperto, no processo atual (Situação 1), FIGURA 4, na qual percebeu-se que para a curva reprovada (NOK), o valor do gradiente de torque (GM) é maior que o valor da curva OK.

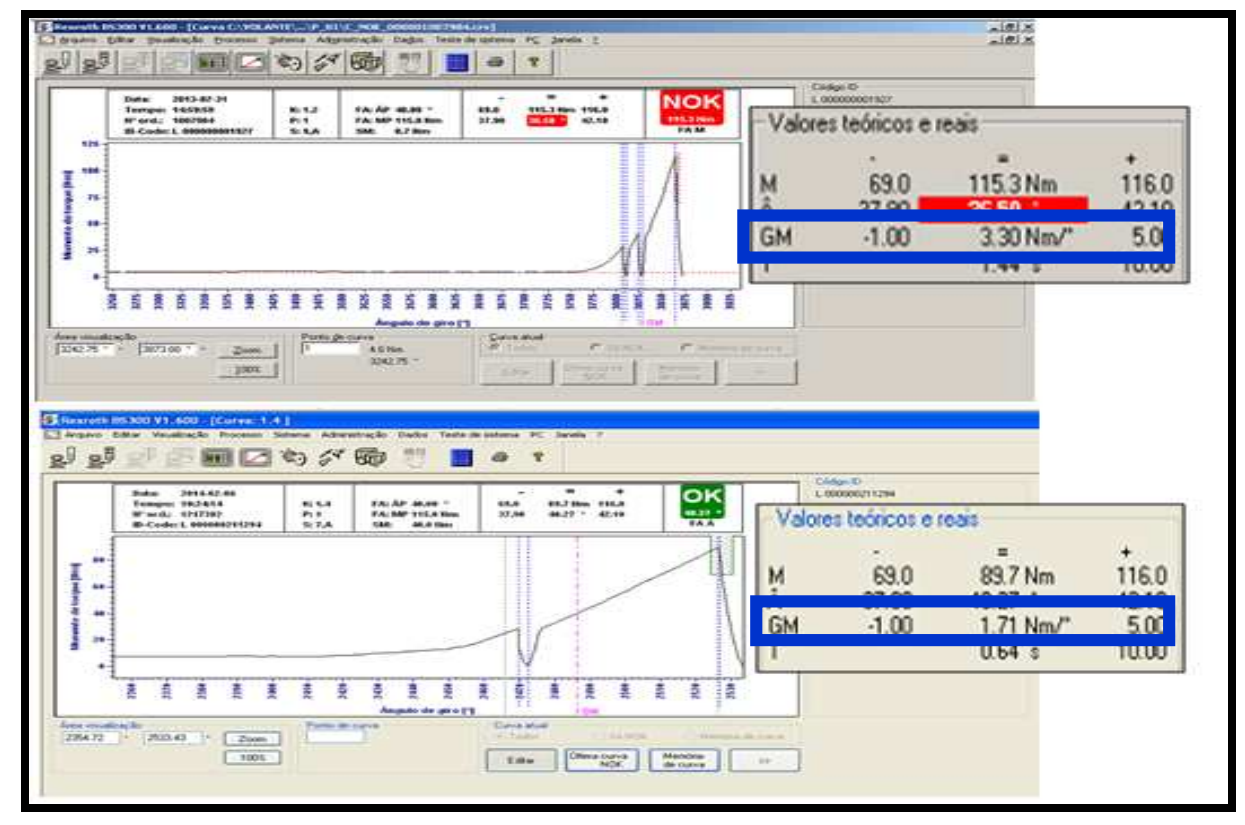

FIGURA 4 - Curvas de aperto OK e NOK para análise FONTE: Cristian Carlo Gonçalves da Costa (2015)

Em seguida realizou-se a sobreposição das curvas OK e NOK, onde pode-se observar as etapas de aperto do parafuso em ambos os casos, conforme FIGURA 5. 


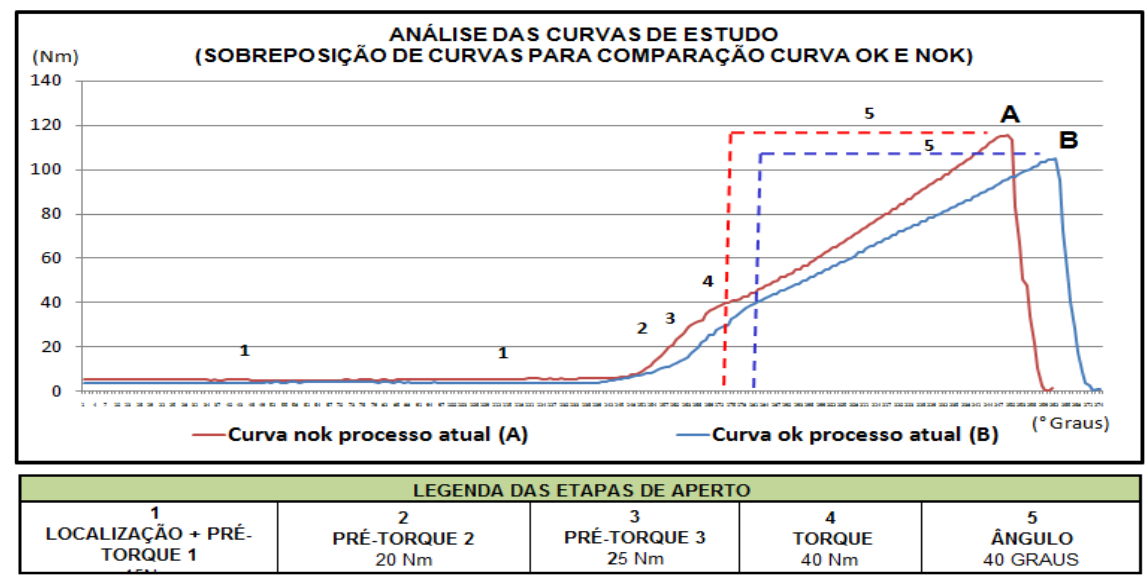

FIGURA 5 - Curvas de aperto OK e NOK sobrepostas FONTE: Cristian Carlo Gonçalves da Costa (2015)

É possível perceber na FIGURA 5, uma inclinação da curva NOK (A) maior em relação à curva OK (B) das etapas 2 a 5 . Já durante a etapa 1 as condições de aperto são muito semelhantes.

A observação no posto de trabalho foi realizada diariamente, nos anos de 2014 e 2015, com a participação e colaboração dos responsáveis técnicos e operacionais do processo registrando os fatos mais relevantes, conforme segue abaixo:

\section{Fato 1}

O acabamento dos parafusos que chegam à borda de linha não é adequado ao processo, conforme resultados apresentados na FIGURA 6.

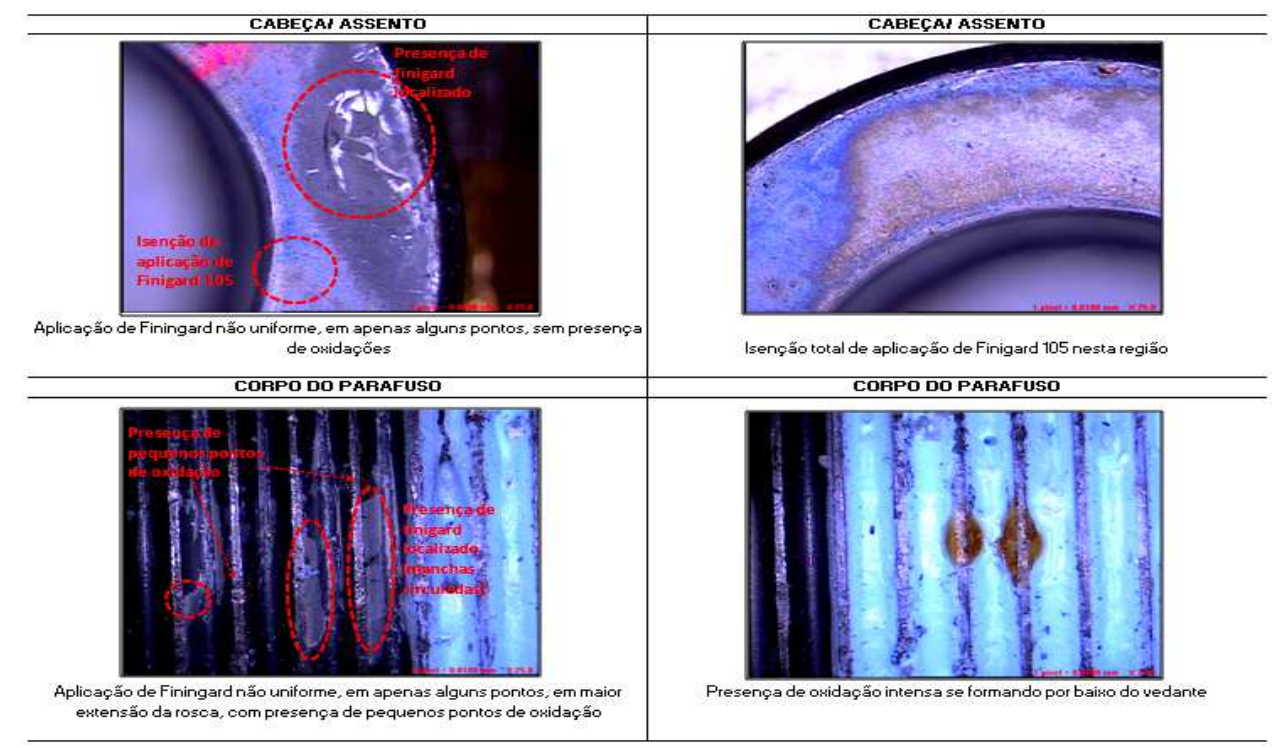

FIGURA 6 - Condição física do assento e corpo parafuso e oleamento (Optiv Classic 45X) FONTE: Cristian Carlo Gonçalves da Costa (2015)

\section{Fato2}


Quanto ao modo operacional nenhum tipo de modo de falha foi observado, uma vez que o parafuso é pré-montado ou aproximado de forma manual, e sem nenhum tipo de risco de interferência no processo de aperto.

\section{Fato 3}

Durante as observações foram realizados experimentos com o óleo do motor, mais especificamente o SAE 20W/40, com intuito de descobrir se o fator óleo interfere no processo de torque, mais precisamente se esse elimina ou minimiza os problemas de reprovação, e os efeitos da interação do óleo durante o aperto, buscando utilizálo como uma possível contenção, ou até mesmo uma das soluções definitivas para o problema em questão.

Como resultado inicial desse experimento, aplicando uma camada muito fina de óleo (média de $71 \mathrm{mg}$ ) diretamente na flange do volante, na região onde a cabeça do parafuso se acomoda, é possível afirmar que não houve arraste de material, e as marcas do aperto se apresentaram uniformes em todas as amostras conforme mostra a FIGURA 7.

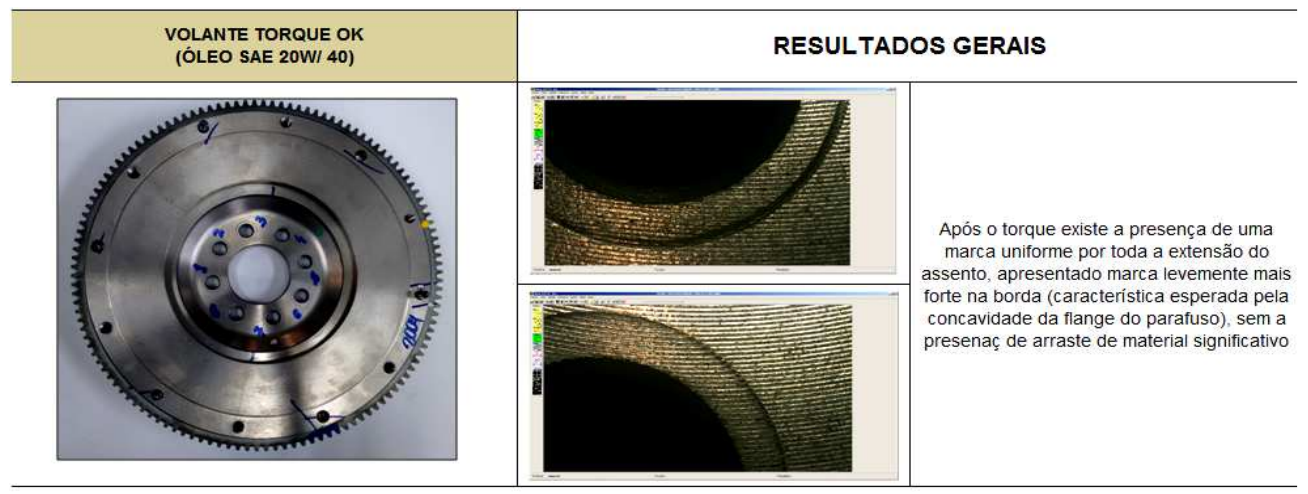

FIGURA 7 - Avaliação da flange do parafuso após torque ok (Optiv Classic 45X) FONTE: Cristian Carlo Gonçalves da Costa (2015)

Os resultados de torque obtidos e análises desse experimento foram utilizados como fonte de comparação e são apresentados a seguir.

Após as observações do posto de trabalho foi realizada uma auditoria focada no processo de fabricação do parafuso e no processo de oleamento com Finigard 105, com intuito de buscar possíveis causas e possíveis melhorias nos processos. Como resultados foram levantados pontos de melhoria na garantia do tempo de cura do filme de óleo (verniz) e também melhoria da drenagem do óleo antes de iniciar a sua cura na centrífuga.

Para que seja atendida a especificação de secagem em centrífuga de 10 minutos a $80^{\circ} \mathrm{C}$ e $250 \mathrm{rpm}$ (especificação de engenharia através de teses empíricos), é necessária a aplicação de controle automático de tempo e temperatura, além de um equipamento adequado para centrifugação, pois atualmente o processo é manual e o calor e a centrífuga são improvisados. Também é necessário controle de tempo mínimo para a drenagem do produto antes de ser realizada a cura do produto. 
Foi constatado que o Finigard 105, um óleo que após passar por um processo de cura, sela um filme de verniz sobre o parafuso, garantindo a sua proteção à corrosão e exerce a função de moderador de torque desde que as especificações técnicas necessárias para sua aplicação sejam atendidas. Foram realizados testes no fornecedor, onde pode ser observado que sendo dissolvido ou não em água, se não for bem curado, não completa a película de verniz em torno do parafuso, podendo causar os problemas já verificados anteriormente na superfície do parafuso (oxidação e bolhas de verniz), e não atua como um moderador de torque adequado. Outro ponto importante aqui, é que esse produto tem requisito definido para aplicação em peças de zinco, cromados ou galvanizadas, e assim, esse não é adequado para parafusos com acabamento superficial em Oxidação [10].

O processo de aplicação do vedante azul estava em conformidade e com o equipamento em boas condições de operação.

Quanto ao processo de fabricação do parafuso não foram observados problemas técnicos no processo de revenimento, têmpera e armazenagem do parafuso antes do acabamento superficial. Também estava em conformidade o processo final de banho para geração da oxidação negra.

Como o objetivo de avaliação do efeito físico da interação entre as peças, foram observadas peças antes e depois do torque no volante e no flexplate, para comparar o efeito físico do aperto sobre elas conforme seguem nas FIGURAS 8, 9 e 10 e respectivos resultados gerais.

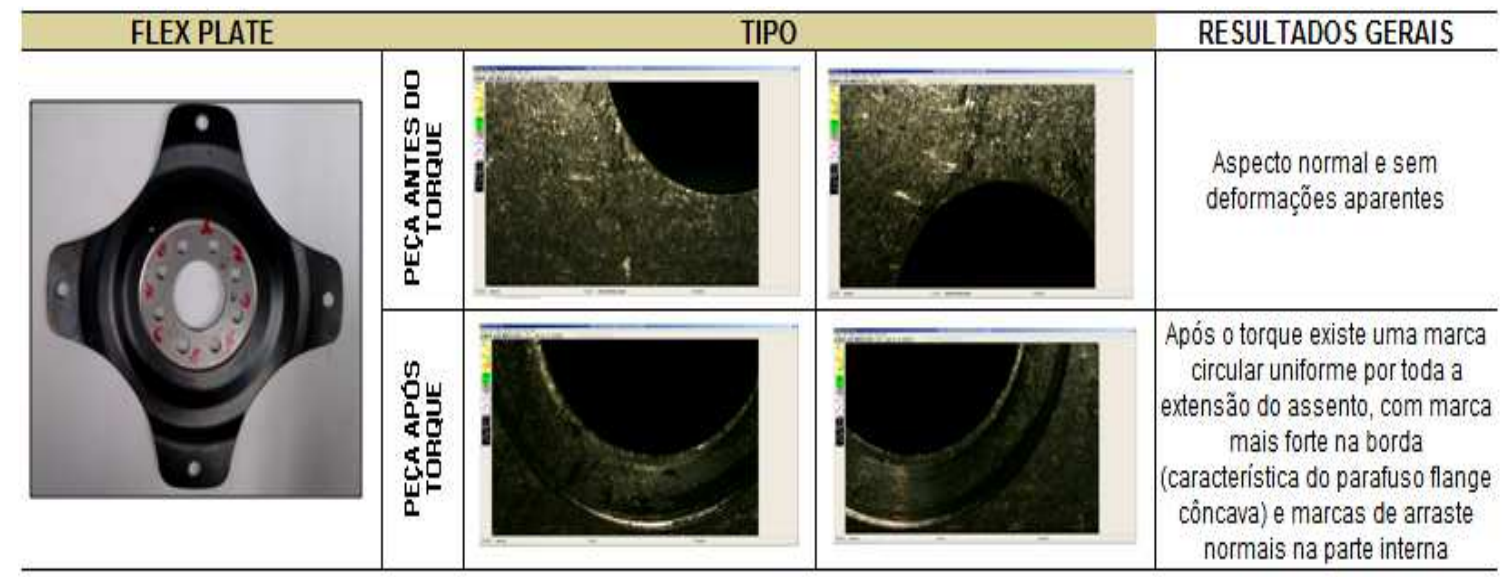

FIGURA 8 - Avaliação do assento flexplate antes e após torque OK (Optiv Classic 45X) FONTE: Cristian Carlo Gonçalves da Costa (2015) 


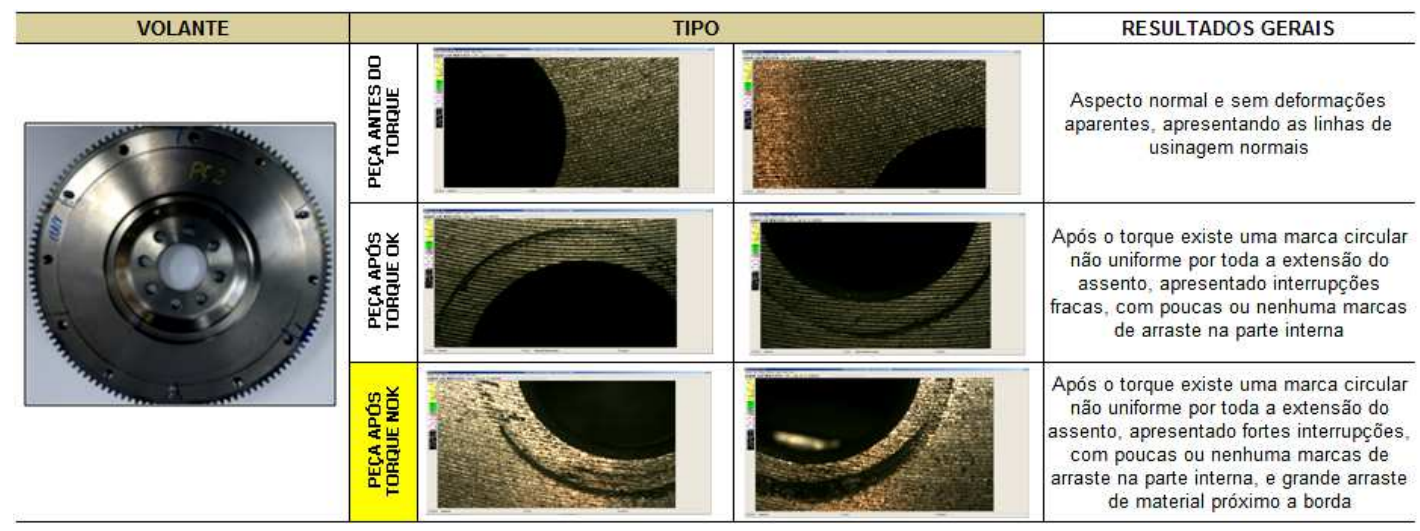

FIGURA 9 - Avaliação do assento volante antes e após torque OK e NOK (Optiv Classic 45X) FONTE: Cristian Carlo Gonçalves da Costa (2015)

\begin{tabular}{|c|c|c|c|c|}
\hline PARAFUSO & \multicolumn{3}{|c|}{ TIPO } & RESULTADOS GERAIS \\
\hline 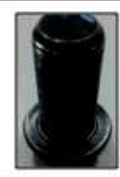 & 离 & i & 8 & $\begin{array}{c}\text { Após o torque existe várias marcas } \\
\text { circulares uniformes por toda a extensão do } \\
\text { assento, apresentado marca levemente mais } \\
\text { forte na borda, sem a presenaç de arraste de } \\
\text { material significativo }\end{array}$ \\
\hline$(52)$ & 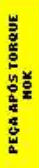 & 85 & $\therefore$ & $\begin{array}{l}\text { Após o torque existe uma marca circular não } \\
\text { uniforme por toda a extensão do assento, } \\
\text { apresentado fortes interrupçóes, e grande } \\
\text { arraste de material próximo a borda } \\
\text { (localizado sempre em uma região) - } \\
\text { fenômeno conhecido como "Galling" }\end{array}$ \\
\hline
\end{tabular}

FIGURA 10 - Avaliação da flange do parafuso após torque OK e NOK (Optiv Classic 45X) FONTE: Cristian Carlo Gonçalves da Costa (2015)

Do estudo comparativo do aperto atual do volante, do aperto com óleo SAE 20W/40 e o aperto do flexplate obtiveram-se os resultados seguintes para torque e gradiente de torque respectivamente:

\section{Resultados para o Torque:}

Na FIGURA 11, tem-se os resultados comparativos de capabilidade para os três processos em análise. Verifica-se que o aperto do flexplate e o aperto com SAE 20W/40 têm altos Cpk e altos Cp. Já o processo de aperto atual se mostra incapaz $(\mathrm{Cpk}<1)$.

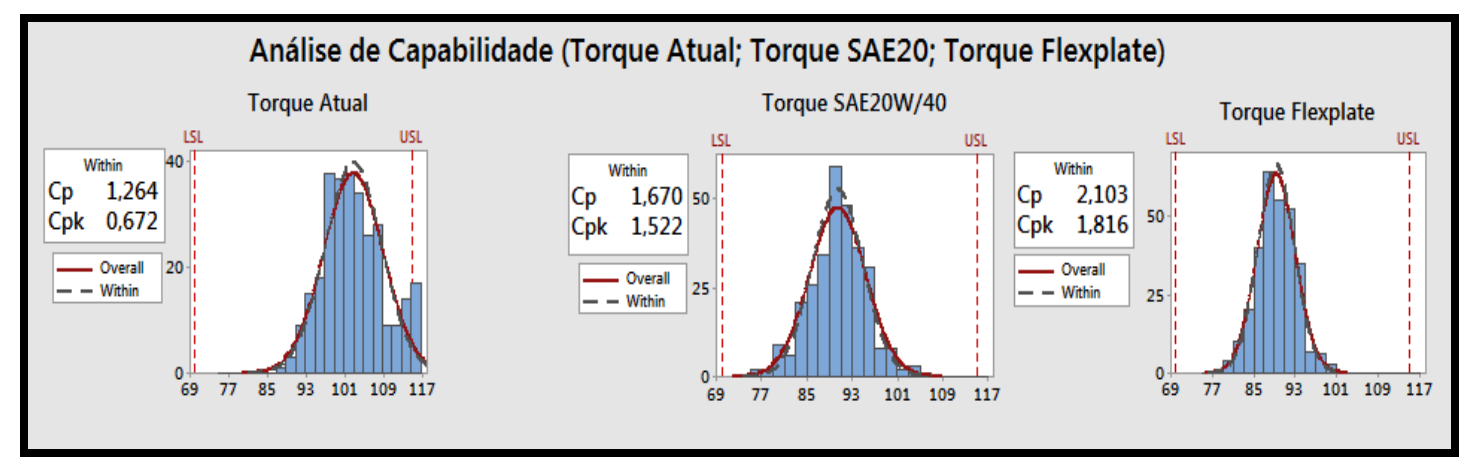

FIGURA 11 - Comparativo das Análises de Capabilidade (TORQUE)

FONTE: Cristian Carlo Gonçalves da Costa (2015) 
Em relação à Análise de Variância, evidenciou-se diferença estatística entre as médias e as dispersões dos três processos, porém o processo de aperto atual é o que possui a média mais afastada e mais significativa em relação aos outros dois processos que possuem médias muito próximas.

\section{Resultados para o Gradiente de Torque:}

$\mathrm{Na}$ análise apresentada na FIGURA 12, foram utilizados os valores teóricos calculados para os limites inferior e superior de gradiente conforme a TABELA 1. Tem-se que os processos de aperto do flexplate e o aperto com óleo SAE 20W/40 têm altos Cpk e Cp, e novamente o processo de aperto atual se mostra extremamente ineficaz $(\mathrm{Cpk}<1)$.

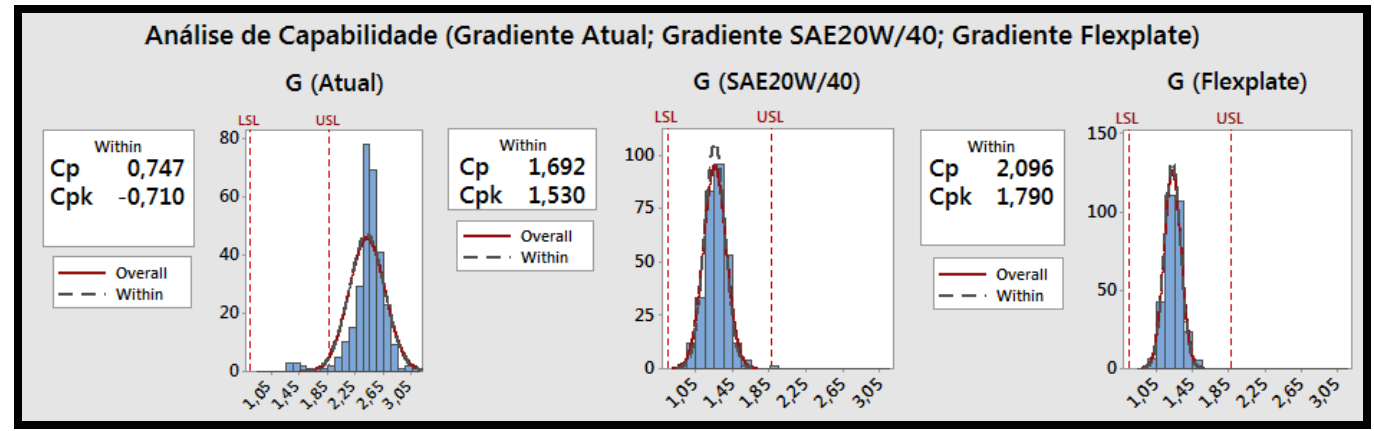

FIGURA 12 - Comparativo das Análises de Capabilidade (GRADIENTE)

FONTE: Cristian Carlo Gonçalves da Costa (2015)

Em relação à análise de variância, foi evidenciada diferença estatística entre as médias e as dispersões dos três processos, porém o processo de aperto atual possui na dispersão e na média uma diferença relevante maior em relação aos demais.

Dos estudos comparativos pode-se correlacionar os valores (coletas de estudo) obtidos nos processos e os valores solicitados em norma (processo teórico) presente na TABELA 1, como forma de comparação geral dos valores de processo atuais para cada tipo de aperto, e verificar quais se adaptam a norma.

\begin{tabular}{|c|c|c|c|c|}
\hline & $\begin{array}{l}\text { TORQUE VOLANTE } \\
\text { NORMAL PRODUÇ.A.O }\end{array}$ & $\begin{array}{c}\text { TORQUE } \\
\text { VOLANTE (SAE 20W/40) }\end{array}$ & $\begin{array}{c}\text { TORQUE } \\
\text { FLEXPLATE }\end{array}$ & $\begin{array}{l}\text { PROCESSO TEORICO } \\
\text { (NORMA TORQUE) }\end{array}$ \\
\hline YALOR SUPERIOR & 116,00 & 105,50 & 100,70 & $115 !$ \\
\hline YALOR INFERIOR & $87,70 !$ & 75,70 & 79,30 & 70 \\
\hline MÉDIA (NOMINAL) & 103,03 & 90,51 & 89,43 & NOMINAL \\
\hline DESYIO PADRÁ MÉDIO & 5,05 & 3,85 & 2,95 & $-\infty$ \\
\hline \multirow[t]{2}{*}{ DESYIO PADRAOO } & 6,23 & 5,01 & 3,73 & \\
\hline & $\begin{array}{c}\text { GRADIENTE } \\
\text { VOLANTE NORMAL } \\
\text { PROEUŞAO }\end{array}$ & $\begin{array}{c}\text { GRA.DIENTE } \\
\text { VOLANTE (SAE 20W/40) }\end{array}$ & $\begin{array}{l}\text { GRAADIENTE FLEX } \\
\text { PLATE }\end{array}$ & $\begin{array}{l}\text { PROCESSO TEORICO } \\
\text { (NORMA GRADIENTE) }\end{array}$ \\
\hline YALOR SUPERIOR & 3,07 & 1,89 & 1,53 & 1,88 \\
\hline YALOR INFERIOR & 1,26 & 0,89 & 1,00 & 0,75 \\
\hline MÉDIA [NOMINAL] & $2,42 !$ & 1,26 & 1,23 & NOMINAL \\
\hline DESYIO PADRÃO MÉDIO & 0,17 & 0,09 & 0,08 & 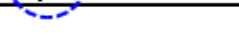 \\
\hline DESYIO PADRAO & 0,26 & 0,13 & 0,09 & \\
\hline
\end{tabular}

TABELA 1 - Análise comparativa dos processos em relação à especificação em Norma FONTE: Cristian Carlo Gonçalves da Costa (2015) 
Como resultado, tomando como base a TABELA 1, conclui-se que, o processo atual é o único que não atende a Norma em vigor em relação aos valores de torque e aos valores teóricos de gradiente necessários para garantir a janela final de torque para um ângulo de $40^{\circ}$.

$\mathrm{Na}$ comparação das rugosidades foram traçadas e avaliadas 25 amostras de perfis de rugosidade do volante e do flexplate e analisadas em relação à análise de variância, na qual foi evidenciada diferença estatística entre as médias e as dispersões dos parâmetros de rugosidade "Ra", "Rz" e "Rt", sendo os valores do volante maiores que do flexplate. Ou seja, tem-se maior rugosidade para o volante conforme FIGURAS 13. Somente no caso das dispersões, para Rt não houve diferenças significativas entre as peças, o que já era esperado.

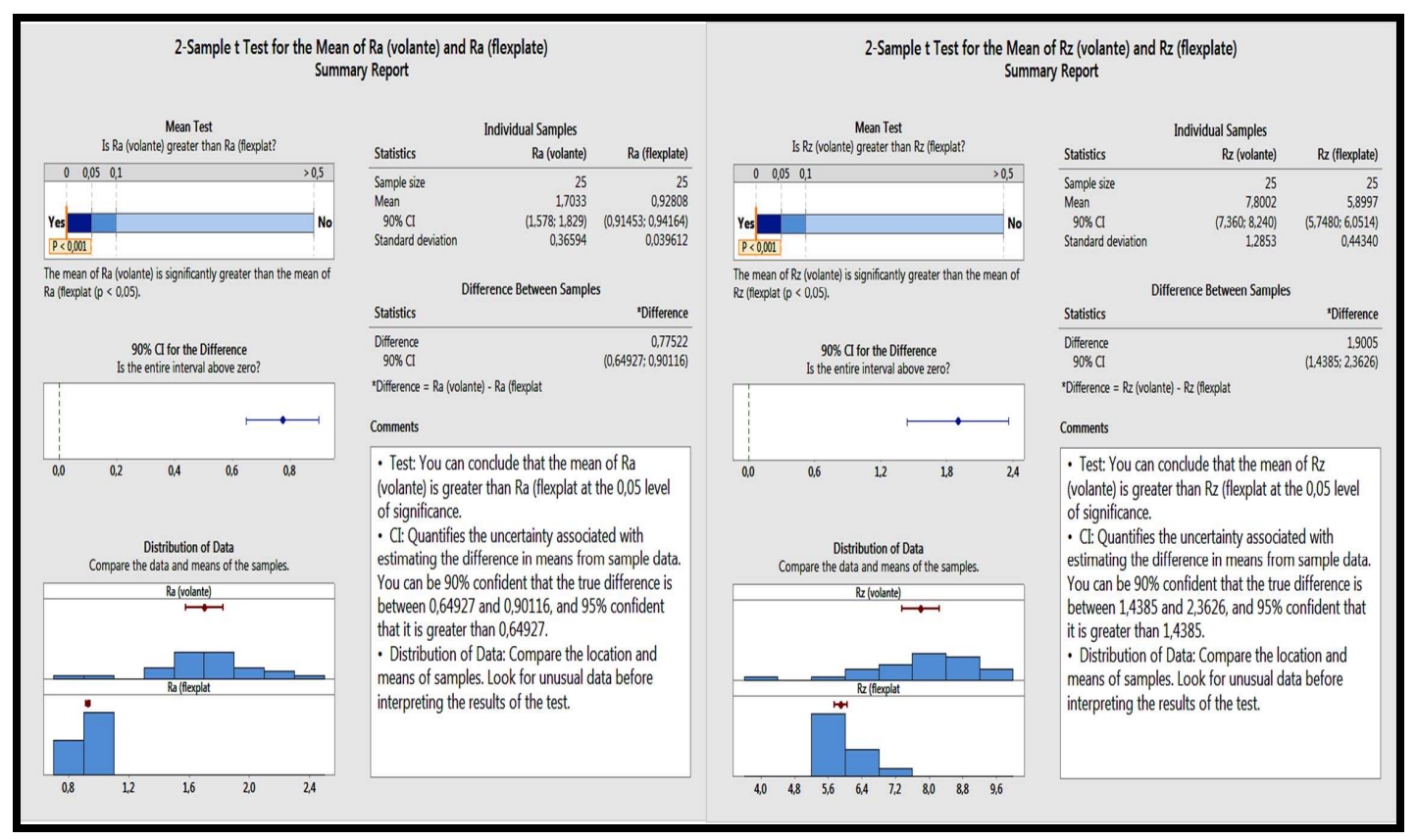

FIGURA 13 - Análise de Variância para as rugosidades do volante e do flexplate (Ra e Rz) FONTE: Cristian Carlo Gonçalves da Costa (2015)

Para melhor visualizar as diferenças de rugosidade, segue as representações gráficas dos perfis do flexplate e do volante, respectivamente na FIGURA 14.

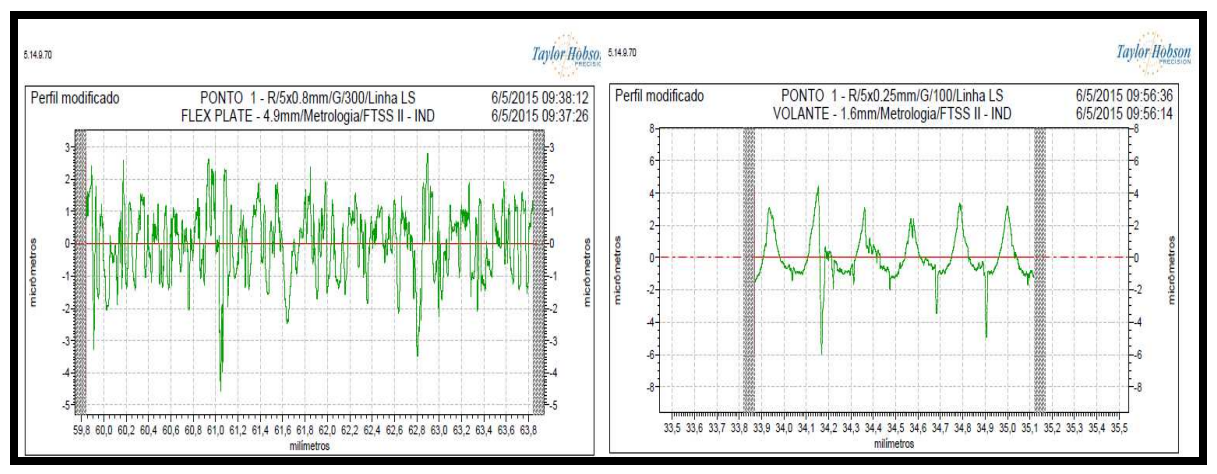

FIGURA 14 - Perfil de rugosidade do Flexplate e Volante FONTE: Cristian Carlo Gonçalves da Costa (2015) 
Também foram traçadas e avaliadas 5 amostras de perfis de parafuso com acabamento em oxidação negra conforme TABELA 2 e FIGURA 15.

\begin{tabular}{c|c|c|c}
\cline { 2 - 4 } & \multicolumn{3}{c}{$\begin{array}{c}\text { VALORES MÉDIOS PARA ANÁLISE } \\
\text { ACABAMENTO DO PARAFUSO EM OXIDAÇÃo NEGRA } \\
(\boldsymbol{\mu m})\end{array}$} \\
\cline { 2 - 4 } & $\mathrm{Ra}$ (oxid) & Rt (oxid) & $\mathrm{Rz}$ (oxid) \\
\hline PC1 & 1,2478 & 6,3571 & 4,3312 \\
\hline PC2 & 1,0108 & 5,3519 & 3,8090 \\
\hline PC3 & 1,0906 & 5,1807 & 3,4337 \\
\hline PC4 & 1,1013 & 4,6627 & 3,4968 \\
\hline PC5 & 0,2734 & 1,6787 & 3,2167 \\
\hline MÉDIAS & 0,9448 & 4,6462 & 3,2575 \\
\hline
\end{tabular}

TABELA 2 - Análise dos valores de rugosidade do parafuso com acabamento em oxidação negra FONTE: Cristian Carlo Gonçalves da Costa (2015)

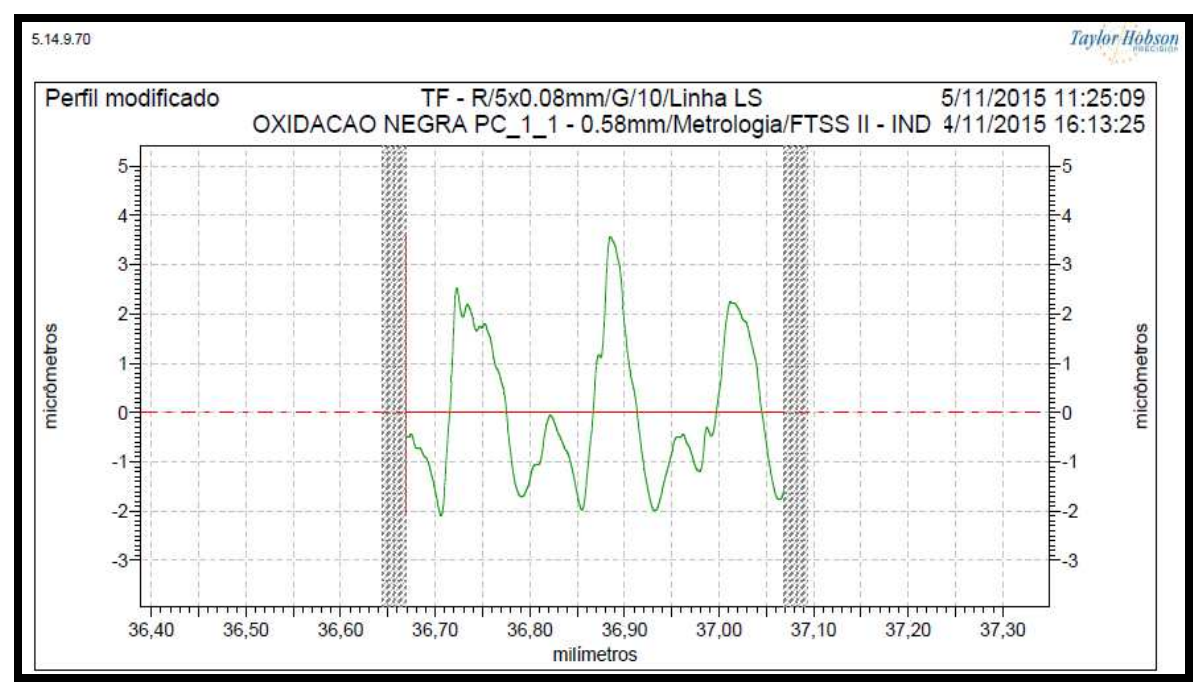

FIGURA 15 - Perfil de rugosidade do Parafuso com acabamento em oxidação negra FONTE: Cristian Carlo Gonçalves da Costa (2015)

Avaliando somente os parâmetros de amplitude de rugosidade do volante, flexplate e parafuso, pode-se apenas concluir que a rugosidade do volante é maior que do flexplate, uma vez que o parafuso é o elemento comum na interação realizada durante o torque, sem elemento para comparações até o momento. No entanto percebe-se que a rugosidade média dos parâmetros do parafuso tem valores baixos e próximos aos valores do flexplate.

Para reforçar a avaliação da rugosidade e buscar novos resultados foram medidos os parâmetros híbridos "RHSC" e "RPc" Como altura média ou valor de referência para o cálculo de RHSC, foi utilizado o valor $0 \mu \mathrm{m}$ para análise, ou seja, o cálculo do número de picos acima desse valor a partir da linha vermelha que passa em 0 nas FIGURAS 15 e 16. Já para o RPc foi utilizada uma largura de faixa (área delimitada por $\mathrm{C} 1$ e C2) no valor de $1 \mu \mathrm{m}$ com centro na origem também. Os valores médios encontrados para os parâmetros podem ser observados na TABELA 3. 


\begin{tabular}{|c|c|c|c|c|c|c|c|}
\hline & \multicolumn{3}{|c|}{$\begin{array}{l}\text { VALORES MÉDIOS DE RHSC } \\
\text { ALTURA MÉDIA }(0 \mu \mathrm{m})\end{array}$} & & \multicolumn{3}{|c|}{$\begin{array}{l}\text { VALORES MÉDIOS DE RPC } \\
\text { LARGURA MÉDIA (1 } 1 \mu \mathrm{m})\end{array}$} \\
\hline & VOLANTE & FLEXPLATE & $\begin{array}{c}\text { PARAFUSO } \\
\text { (OXIDAÇÃO NEGRA) }\end{array}$ & & VOLANTE & FLEXPLATE & $\begin{array}{c}\text { PARAFUSO } \\
\text { (OXIDAÇÃ̃O NEGRA) }\end{array}$ \\
\hline $\mathrm{PC1}$ & 11,00 & 70,00 & 3,00 & PC1 & 80,00 & 120,00 & 66,67 \\
\hline $\mathrm{PC2}$ & 9,00 & 66,00 & 3,00 & PC2 & 56,00 & 112,50 & 58,33 \\
\hline PC3 & 11,67 & 61,33 & 3,00 & PC3 & 56,00 & 110,83 & 58,33 \\
\hline PC4 & 11,33 & 71,00 & 2,67 & PC4 & 77,33 & 129,17 & 66,67 \\
\hline PC5 & 9,67 & 63,33 & 7,00 & PC5 & 53,33 & 113,33 & 16,67 \\
\hline $\mathrm{PC6}$ & 8,33 & 75,67 & - & PC6 & 53,33 & 123,33 & $\cdot$ \\
\hline PC7 & 8,33 & 64,33 & $\cdot$ & PC7 & 64,00 & 119,17 & - \\
\hline VALORES MÉDIOS & 9,90 & 67,38 & 3,73 & VALORES MÉDIO & 62,86 & 118,33 & 53,33 \\
\hline
\end{tabular}

TABELA 3 - Tabela de valores médios comparativos de RHSC e RPc FONTE: Cristian Carlo Gonçalves da Costa (2015)

Com os resultados dos dois parâmetros híbridos nas tabelas acima, pode-se perceber que os valores de "RHSC" e "RPc" para o volante e o parafuso são mais baixos e mais próximos, enquanto os valores do flexplate são bem maiores.

Para finalizar a explicação dos resultados obtidos, foi realizada a comparação e a avaliação do resultado dos alongamentos do parafuso nas condições normais de aperto com e sem o óleo SAE 20W/40. Como resultado da análise de variância não foram evidenciadas diferenças estatísticas significativas entre os alongamentos, concluindo-se assim que o óleo SAE 20W/40 pode ser utilizado como contenção, sem gerar riscos de alongamento do parafuso e também sem riscos para a qualidade do produto.

Foram realizadas as coletas iniciais de 250 torques para avaliar o comportamento do parafuso fosfatizado no volante e 250 torques para avaliar o comportamento no flexplate. Como resultados de torque e gradiente, obteve-se, por meio da Análise de Capabilidade de Processo de ambas as peças, os valores mostrados na FIGURA 16.

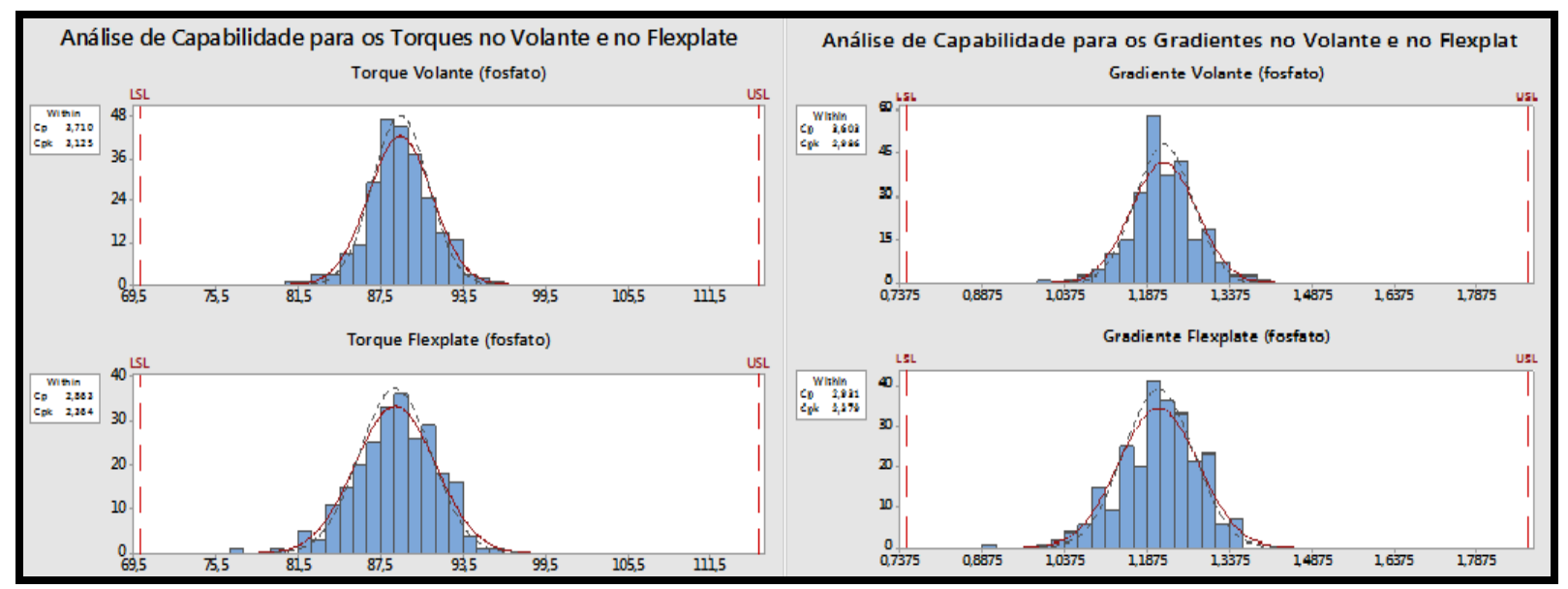

FIGURA 16 - Análise de Capabilidade de Torque e Gradiente para o Volante/Flexplate com parafuso fosfatizado

FONTE: Cristian Carlo Gonçalves da Costa (2015) 
$\mathrm{Na}$ análise acima pode-se verificar que ambos os processos resultaram em excelentes resultados para o $\mathrm{Cp}$ e Cpk, ou seja, ambos bem acima de 1,33. A questão dos valores do flexplate estarem um pouco abaixo do volante já era esperada, uma vez que a rugosidade do flexplate é menor que do volante, ou seja, há uma tendência dos valores de torque e gradiente diminuírem mais que no volante, porém sem riscos para a qualidade dos resultados esperados desse processo. Portanto, o fosfato se mostrou excelente e com grande estabilidade para os valores de torque gradiente.

Também foram avaliadas as superfícies de ambos os produtos após os torques serem realizados, e que podem ser observados nas FIGURAS 17, 18 e 19.

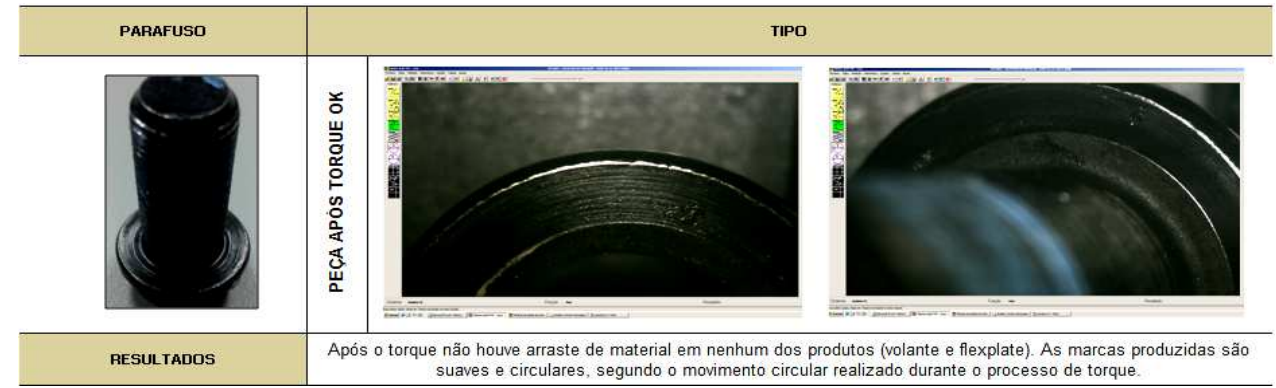

FIGURA 17 - Avaliação da flange do parafuso fosfatizado após torque OK no Volante e Flexplate (Optiv Classic 45X)

FONTE: Cristian Carlo Gonçalves da Costa (2015)

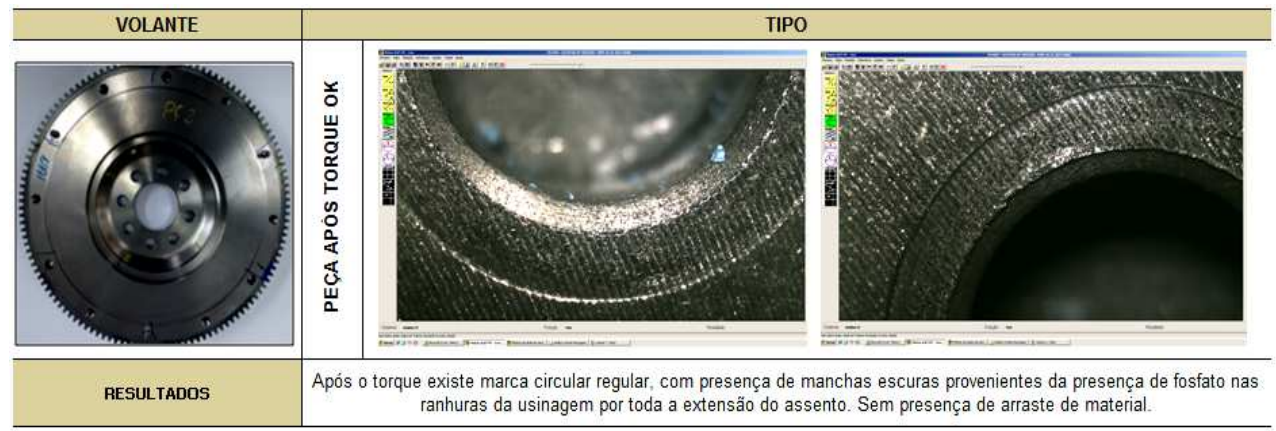

FIGURA 18 - Avaliação da flange do volante após torque OK com o parafuso fosfatizado (Optiv Classic 45X)

FONTE: Cristian Carlo Gonçalves da Costa (2015)

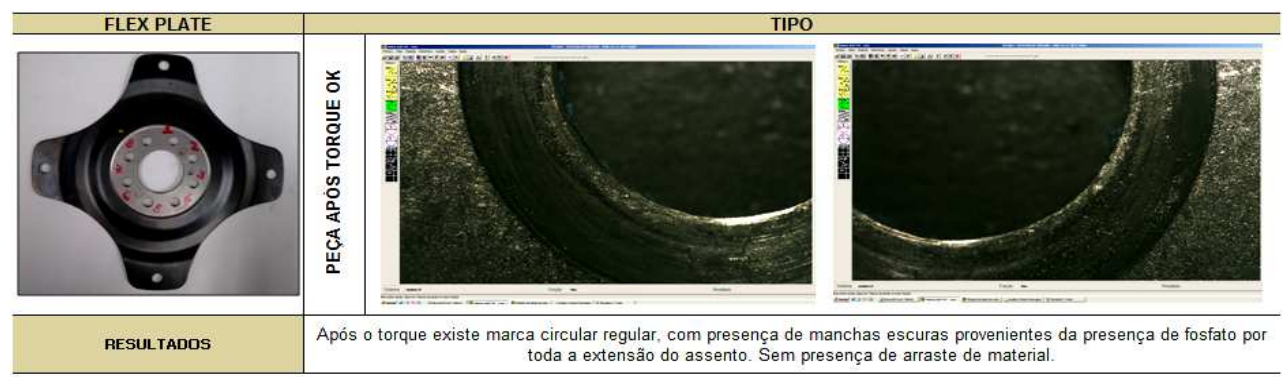

FIGURA 19 - Avaliação da flange do flexplate após torque OK com o parafuso fosfatizado (Optiv Classic 45X)

FONTE: Cristian Carlo Gonçalves da Costa (2015) 
Para avaliar os resultados de torque segue abaixo uma curva gráfica de torque obtida com o parafuso fosfatizado e o comparativo desse processo de aperto com os processos anteriores em Excel, respectivamente nas FIGURAS 20 e 21.

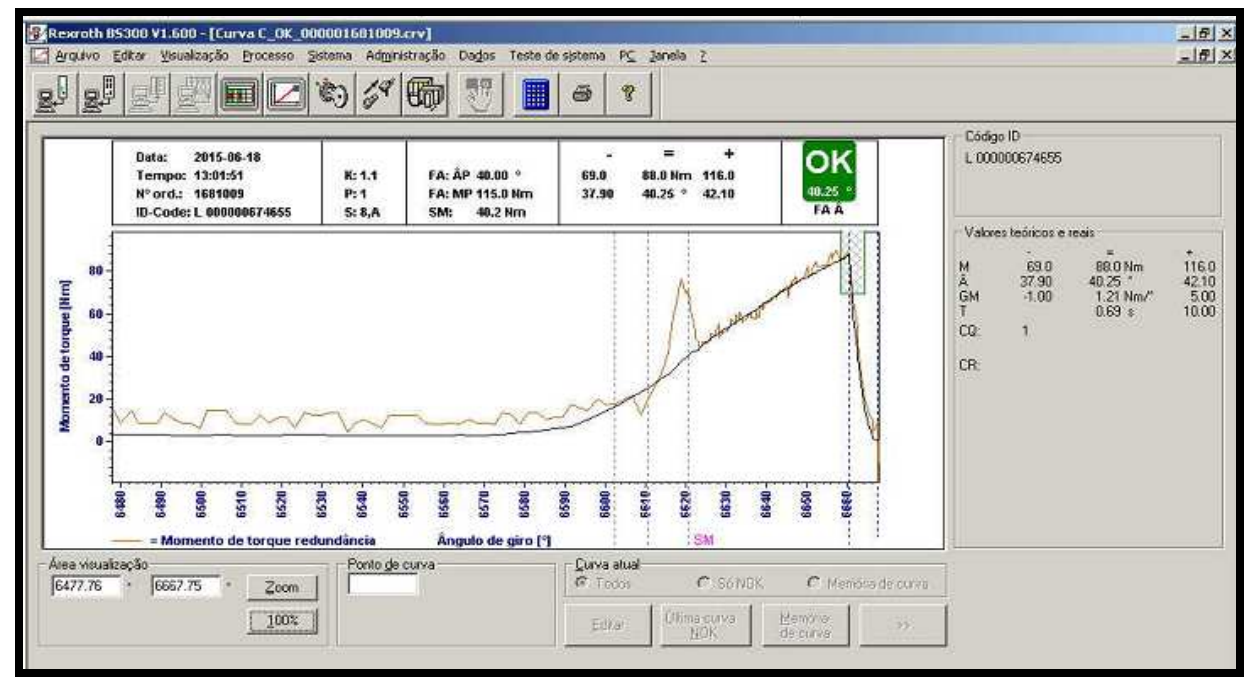

FIGURA 20 - Curva de aperto para o parafuso fosfatizado FONTE: Cristian Carlo Gonçalves da Costa (2015)

Como pode se observado nas FIGURAS 17, 18 e 19, a interação das peças com o parafuso fosfatizado ocorre de forma regular e sem a presença de arraste de material, ou seja, o fosfato é um excelente acabamento superficial, garantindo um bom desempenho do sistema de aperto em questão conforme FIGURA 20.

O perfil de rugosidade do parafuso com acabamento fosfatizado também foi traçado e analisado conforme FIGURA 21.

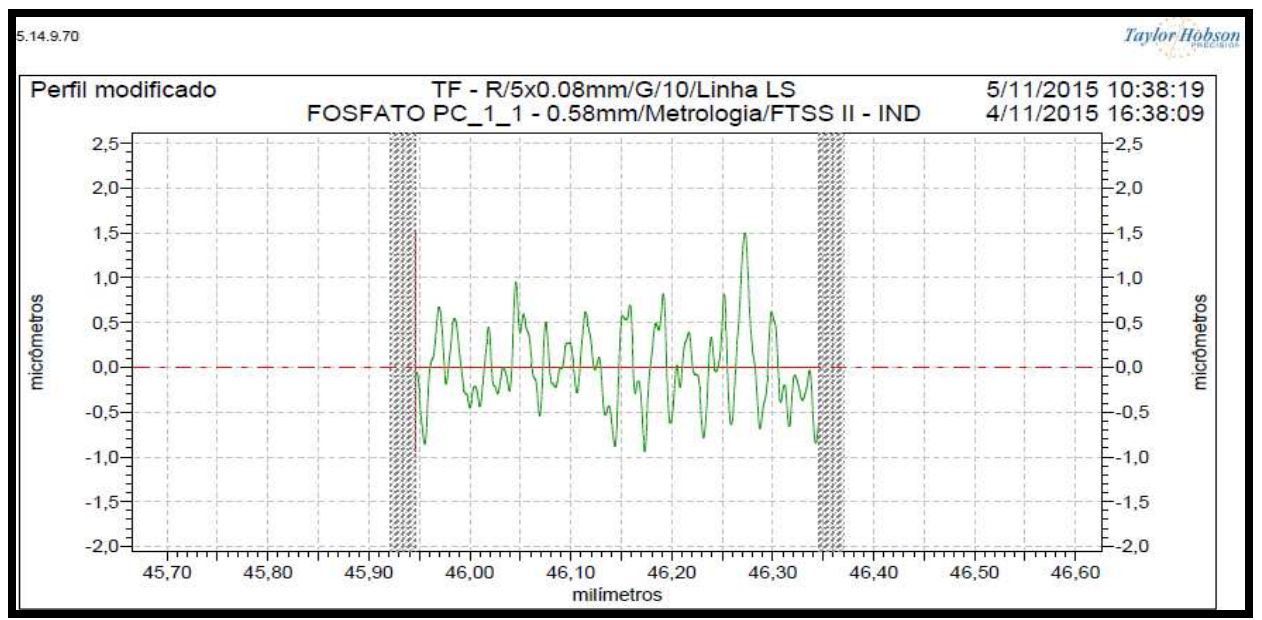

FIGURA 21 - Perfil de rugosidade do Parafuso com acabamento fosfatizado FONTE: Cristian Carlo Gonçalves da Costa (2015)

Os parâmetros de amplitude e híbridos dos parafusos com acabamento em oxidação negra e fosfatizado foram comparados, conforme TABELA 4 e 5 respectivamente, e avaliados estatisticamente, onde não foram observadas diferenças significativas segundo uma análise de variância. 


\begin{tabular}{c|c|c|c|c|c|c}
\cline { 2 - 7 } & \multicolumn{7}{c}{ VALORES MÉDIOS PARA ANÁLISE } \\
\cline { 2 - 7 } & Ra (fosf) & Ra (oxid) & Rt (fosf) & Rt (oxid) & Rz (fosf) & Rz (oxid) \\
\hline PC1 & 0,4431 & 1,2478 & 3,4096 & 6,3571 & 2,2478 & 4,3312 \\
\hline PC2 & 0,7350 & 1,0108 & 5,4503 & 5,3519 & 3,4716 & 3,8090 \\
\hline PC3 & 0,7470 & 1,0906 & 7,0023 & 5,1807 & 3,9362 & 3,4337 \\
\hline PC4 & 0,6464 & 1,1013 & 5,0569 & 4,6627 & 3,3526 & 3,4968 \\
\hline PC5 & 0,8346 & 0,2734 & 6,9817 & 1,6787 & 4,4325 & 1,2167 \\
\hline VALORES MÉDIOS & 0,6812 & 0,9448 & 5,5802 & 4,6462 & 3,4882 & 3,2575 \\
\hline
\end{tabular}

TABELA 4 - Análise comparativa dos parâmetros de amplitude do parafuso fosfatizado e com oxidação negra

FONTE: Cristian Carlo Gonçalves da Costa (2015)
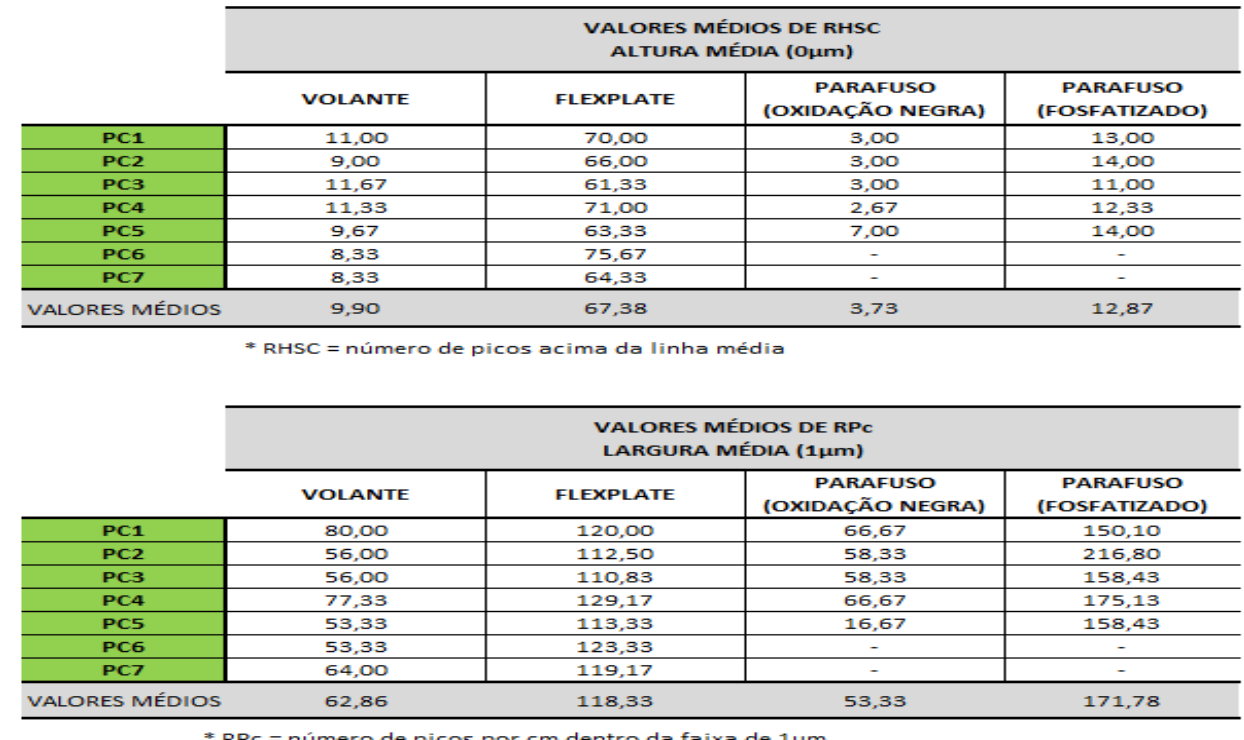

TABELA 5 - Tabela de valores médios comparativos de RPc e RHSC (volante, flexplate, parafuso com oxidação negra e parafuso fosfatizado)

FONTE: Cristian Carlo Gonçalves da Costa (2015)

\section{CONCLUSÕES}

Os objetivos iniciais deste estudo foram atendidos, ou seja, a causa das reprovações foi compreendida, e uma solução foi estudada, testada e já está em validação pela engenharia da empresa. Também foi de extrema importância os estudos de normas internas e artigos relacionados a torque, o qual gerou conhecimento e prática para aplicação em novos desafios dentro da empresa.

Quanto ao paradigma da utilização de óleo no parafuso para minimizar as perdas, o mesmo já está sendo aplicado como contenção até que seja validado a solução final.

Com relação ao método de aperto, Torque mais Ângulo de Deslocamento, pode-se concluir que independente da força tensora desejada e da sua relação linear com o ângulo, o monitoramento realizado no processo em questão é sobre o Torque Final obtido, e este não segue a mesma relação, mesmo se tratando de um aperto na região elástica. O Torque Final possui grande dispersão, devido a sua forte 
dependência em relação aos coeficientes de atrito $\left(\mu_{\mathrm{G}}\right.$ e $\left.\mu_{\mathrm{K}}\right)$ e à interação dos elementos de fixação.

O acabamento superficial do parafuso (Oxidação Negra + Finigard105) não é adequado e não garante as condições de proteção à corrosão, e nem tampouco garante um controle adequado do coeficiente de atrito, o que certamente contribui para a dispersão atual do Torque Final.

Quanto à superfície do volante e do flexplate, se pode concluir que para a condição atual do parafuso, o flexplate garante um bom processo de aperto em virtude dos seus baixos parâmetros de rugosidade, que, segundo Bueno [11], tem influência significativa na determinação do coeficiente de atrito. Ou seja, deve-se entender que atrito é a resposta da interação das superfícies de forma padronizada [8], e assim pode-se também concluir que o coeficiente de atrito na interação parafuso/flexplate é menor que na interação parafuso/volante em função dos parâmetros de rugosidade.

Das análises comparativas de rugosidade, pode-se concluir com a análise dos parâmetros "RHSC" e "RPc" que o volante e o parafuso oxidado têm um espaçamento entre os picos (asperezas) maior que o flexplate. Ou seja, quanto menor o espaçamento entre picos (maior o número RPc e RHSC), menor a interferência durante a interação das peças, resultando em um melhor deslizamento entre as peças.

No caso do parafuso fosfatizado constatou-se que o processo de fosfatização diminuiu o espaçamento entre os picos devido ao preenchimento dos espaçamentos, o que pode ser observado na FIGURA 22, gerando maiores valores para "RPc" e "RHSC" e conseqüentemente melhorando o deslizamento sobre a superfície do volante. Os valores também ultrapassaram os parâmetros do flexplate mantendo a correlação e, assim, mantendo um bom deslizamento sobre o mesmo.

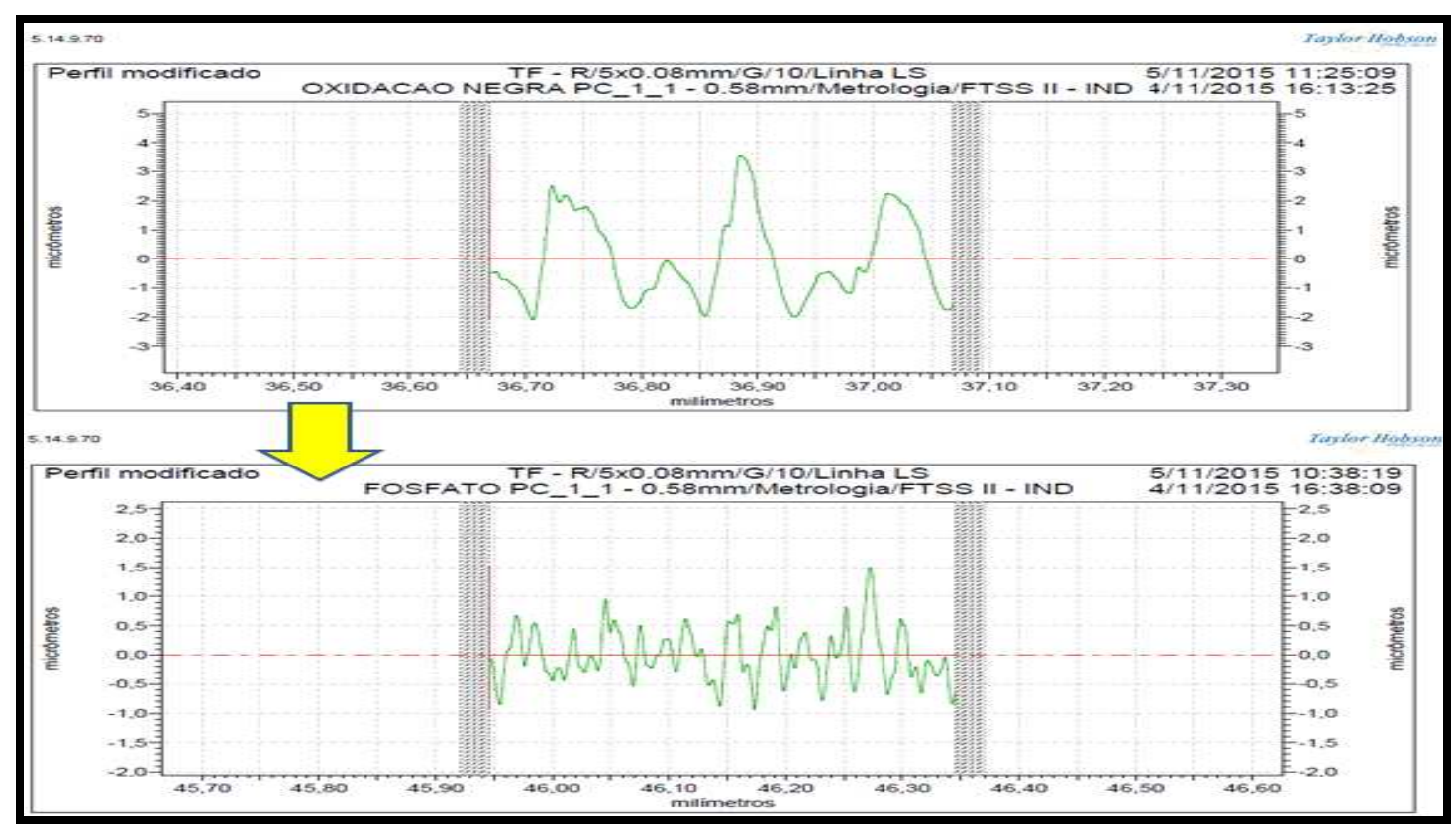

FIGURA 22 - Perfil de rugosidade do parafuso com acabamento fosfatizado FONTE: Cristian Carlo Gonçalves da Costa (2015) 
Pode-se também concluir que a utilização do óleo SAE 20W/40 altera a condição de atrito na interação parafuso/volante, minimizando e trazendo maior estabilidade ao coeficiente de atrito, uma vez que esse age como elemento de preenchimento minimizando as imperfeições existentes na superfície do volante . Ou seja, o óleo em questão diminui e estabiliza o coeficiente de atrito dessa interação, de modo que pode ser utilizado como uma contenção ou uma alternativa para minimizar e, até mesmo resolver, as reprovações de torque, uma vez que a sua utilização não altera o alongamento do parafuso e nem implica em deterioramento de condições de funcionamento originais do projeto a que foi concebido.

Das análises comparativas de gradiente de torque, conclui-se que a definição e o monitoramento deste pode ser uma forma indireta e eficiente de monitorar alterações na condição de atrito do aperto.

Nesse processo, em função dos resultados encontrados, conclui-se que o coeficiente de atrito da cabeça $\left(\mu_{\kappa}\right)$ é o que tem maior impacto sobre a capabilidade do processo em questão.

O parafuso fosfatizado, de todos os acabamentos, foi o que apresentou melhor desempenho, ou seja, maior estabilidade e melhores índices de capabilidade, constituindo assim uma excelente solução para o problema em questão.

Conclui-se que existem alguns pontos que devem ser avaliados para melhorar o processo de aperto em questão, além da alteração do tratamento superficial do parafuso, tais como:

1. Definir tratamento protetivo ou melhorar a questão de tempo e modo de armazenamento para o volante do motor para evitar a oxidação do mesmo, uma vez que esse fato impacta diretamente no coeficiente de atrito;

2. Como não é possível realizar o processo de torque na vertical, recomenda-se mudar o conceito da máquina adaptando-a para um conceito "stop station", ou seja, implementar um projeto onde a máquina fique parada e com sustentação na parte inferior;

3. Uma melhoria rápida e importante para o processo é a eliminação da reação do pino de centralização do volante, ou seja, garantir que o mesmo fique faceado no virabrequim de forma livre sem forças de resistência;

4. Implantar controles automáticos de tempo e temperatura no processo de aplicação do FINIGARD 105 do fornecedor até que esse verniz seja substituído ou eliminado do processo de tratamento do parafuso.

\section{REFERÊNCIAS}

[1] Guia dos Pilares Técnicos. FAPS- Fiat Group Automobiles Production System. Betim, 2008.

[2] Norma FIAT - FPW1.00101/84, "Coppie Di Serraggio Organi Importanti Motore E-TorqQ (ex TRITEC)", 2013.

[3] Norma FIAT - FPW.80104, "Reference of Fasteners", 2013.

[4] NASCIMENTO JR., H. Dissertação de Mestrado ESTUDO DA RELAÇÃo TORQUE X FORÇA TENSORA E DO COEFICIENTE DE ATRITO TENSORA E DO COEFICIENTE DE ATRITO, Belo Horizonte, Minas Gerais, 2003 
[5] CONVENTYA S.A.S. FINIGARD 105 TECHNICAL DATA SHEET. Clichy, França,1995. Disponível em: <

http://www.pmdchemicals.co.uk/ds/Finigard\%20105.pdf>. Acesso em 01/07/2014

[6] LEITE, M. P. Técnicas de aperto e o uso combinado do controle de gradiente/ Parte 1. Revista do Parafuso, n.15, São Bernardo do Campo, São Paulo, Abril, 2009. Disponível em:

$<$ http://www.revistadoparafuso.com.br/v1/modelo/noticia. $p h p ? i d=130>$. Acesso em 28/02/2015.

[7] PIRATELLI, A.; Rugosidade Superficial. Brasília, 2011. Disponível em: $<$ http://www.posgrad.mecanica.ufu.br/metrologia/arquivos/Palestra_UFU_17_ 05_2011.pdf>. Acesso em 05/11/2014.

[8] HUTCHINGS, I.M., "Tribology: Friction and Wear of Engineering Materials", CRC Press, England, UK, 1992.

[9] MUNIZ, J.M. Dissertação de Mestrado Fenômenos Tribológicos Intrínsecos ao Travamento de Juntas de Engenharia Aparafusadas: 0 rosqueamento na indústria automotiva: Sua utilização como recurso de união de juntas desmontáveis. Escola Politécnica da USP, São Paulo, 2007.

[10] HUNT, F.; TATHAM, D. Black oxide passes hydrogen-embrittlement test. Machine Design. Cengage Learning Inc. Vol.73(11), p.80, June, 2001.

[11] BUENO, A.F. et al. Avaliação da influência da rugosidade superficial sobre o atrito no ensaio de compressão do anel. In: Trabalho apresentado no 66. Congresso Anual da ABM - Internacional, São Paulo, 2011. 